\title{
Understanding and predicting classes of college students who use pornography
}

\author{
Cameron C. Brown \\ Kansas State University \\ Jared A. Durtschi \\ Kansas State University \\ Jason S. Carroll \\ Brigham Young University - Provo, jcarroll@byu.edu \\ Brian J. Willoughby \\ Brigham Young University - Provo
}

Follow this and additional works at: https://scholarsarchive.byu.edu/facpub

Part of the Other Social and Behavioral Sciences Commons

\section{Original Publication Citation}

Brown, C. C. *, Durtschi, J. A., Carroll, J. S., \& Willoughby (2017). Understanding and Predicting Classes of College Students Who Use Pornography. Computers in Human Behavior, 66, 114-121.

\section{BYU ScholarsArchive Citation}

Brown, Cameron C.; Durtschi, Jared A.; Carroll, Jason S.; and Willoughby, Brian J., "Understanding and predicting classes of college students who use pornography" (2016). Faculty Publications. 4366. https://scholarsarchive.byu.edu/facpub/4366 accepted for inclusion in Faculty Publications by an authorized administrator of BYU ScholarsArchive. For more information, please contact ellen_amatangelo@byu.edu. 
Full length article

\title{
Understanding and predicting classes of college students who use pornography
}

\author{
Cameron C. Brown ${ }^{\mathrm{a},}{ }^{*}$, Jared A. Durtschi ${ }^{\mathrm{a}}$, Jason S. Carroll ${ }^{\mathrm{b}}$, Brian J. Willoughby ${ }^{\mathrm{b}}$ \\ a School of Family Studies and Human Services: Marriage and Family Therapy, Kansas State University, Manhattan, KS, USA \\ b School of Family Life, Brigham Young University, Provo, UT, USA
}

\section{A R T I C L E I N F O}

\section{Article history:}

Received 17 May 2016

Received in revised form

25 August 2016

Accepted 7 September 2016

Available online 25 September 2016

\section{Keywords:}

Erotica

Pornography

Sex

Quantitative

\begin{abstract}
A B S T R A C T
Despite the widespread acceptance and use of pornography, much remains unknown about the heterogeneity among consumers of pornography. Using a sample of 457 college students from a midwestern university in the United States, a latent profile analysis was conducted to identify unique classifications of pornography users considering motivations of pornography use, level of pornography use, age of user, degree of pornography acceptance, and religiosity. Results indicated three classes of pornography users: Porn Abstainers $(n=285)$, Auto-Erotic Porn Users $(n=85)$, and Complex Porn Users $(n=87)$. These three classes of pornography use are carefully defined. The odds of membership in these three unique classes of pornography users was significantly distinguished by relationship status, selfesteem, and gender. These results expand what is known about pornography users by providing a more person-centered approach that is more nuanced in understanding pornography use. This research did not receive any specific grant from funding agencies in the public, commercial, or not-for-profit sectors.
\end{abstract}

(C) 2016 Elsevier Ltd. All rights reserved.

\section{Introduction}

In American society, pornography use is seen as normative and is widely used (Carroll et al., 2008, in press; Price, Patterson, Regnerus, \& Walley, 2016; Willoughby, Carroll, Nelson, \& PadillaWalker, 2014). Specifically, some estimates suggest that approximately $60 \%$ of men and $35 \%$ of women have viewed some form of pornography in the past year (Price et al., 2016). Despite its prevalence, current literature offers minimal description of individual pornography users. Previous research offers both negative and positive outcomes from this pornography use. Negative outcomes include being more critical of a partner's body (Albright, 2008), participating in risky sexual behaviors (Carroll et al., 2008; Sinkovic, Stulhofer, \& Bozic, 2012; Wright, 2012; Wright, 2013), more accepting of violence against women (Malamuth, Hald, \& Koss, 2012), greater levels of depressive symptoms (Bridges \& Morokoff, 2011), and less satisfaction in a current sexual relationship (Maddox, Rhoades, \& Markman, 2009; Yucel \& Gassanov, 2010). Positive outcomes include being more sexually educated,

\footnotetext{
* Corresponding author. 326 Justin Hall, 1324 Lovers Lane, Manhattan, KS 66506, USA.
}

E-mail address: browncc@ksu.edu (C.C. Brown). higher satisfaction with one's own body image, and generally being more comfortable with sexuality (Watson \& Smith, 2012).

Despite the high rates of pornography use, prevalence of various outcomes of pornography use, and the pornography industry being an annual multi-billion-dollar industry worldwide (Edelman, 2009), there is no clear picture of actual typologies of pornography users. A better understanding of the frequency, purpose, and secondary gains of pornography use is relevant for social scientists when seeking to best describe and evaluate those that use pornography. Specifically, current pornography literature is grappling with how to best define what pornography is and what it entails (Willoughby \& Busby, 2016). A typology will offer greater detail and depth to characteristics of pornography users. In other words, most studies simply use a measure of reported frequency of pornography use without investigating deeper into other features of pornography users that may distinguish various sub-types of pornography use. The purpose of this study is to fill a gap within the current pornography literature to further describe pornography users by developing typologies or classes of different users in a sample of 457 college students. In forming these classes, we considered motivations behind pornography use patterns, level of pornography use, age of user, degree of pornography acceptance, and religiosity. Next, membership in these classes was predicted by 
relationship status, self-esteem, and gender. A profile analysis of this nature will advance the field of pornography literature by viewing pornography users in a more comprehensive light considering personal characteristics, pornography use frequency, and motivations behind their use patterns.

\section{Individual factors of pornography users}

Despite the growing literature examining pornography and its individual outcomes, few studies have considered descriptive characteristics of pornography users. Creating classes of users will assist us with a more detailed depiction of who these individuals are and their pornography use patterns. This will provide a stronger and more deeply integrated foundation for future research and understanding how to best define pornography and its users. Although not exhaustive, the following summarized scholarly work indicates common themes that are prevalent in established research and therefore are important to include in the potential forming of classes of different types of pornography users.

\subsection{Gender and pornography use frequency}

The largest overarching finding within pornography literature is that individual pornography use is predominantly a male activity (Albright, 2008; Buzzell, 2005; Carroll et al., 2008, in press; Cooper, Galbreath, \& Becker, 2004; Cooper, Morahan-Martin, Mathy, \& Maheu, 2002; Emmers-Sommer, Hertlein, \& Kennedy, 2013; McKee, 2007; Stack, Wasserman, \& Kern, 2004). Although, some popular culture outlets suggest that pornography use is becoming more of an accepted activity among women (Brennan, 2010; Carey, 2011). Carroll et al. (2008) found amongst a diverse sample of emerging adults that $87 \%$ of the men reported using pornography to some extent with approximately $20 \%$ of those men reporting daily or every-other-day use. However, only $31 \%$ of the women sampled reported some level of pornography consumption, and of those, only $3.2 \%$ reported patterns of weekly or more.

Another study corroborated these findings when $75 \%$ of the 11,387 men that participated reported accessing or downloading pornography, while only $41 \%$ of the 3859 women reported doing the same acts (Albright, 2008). Others have found that men doubled women's weekly average of online sexual consumption, $2.83 \mathrm{~h}$ compared to $1.36 \mathrm{~h}$ per week (Cooper et al., 2002). Although not entirely conclusive, these frequency trends are common in the literature with men reporting pornography use at substantially higher rates than women (Bridges \& Morokoff, 2011; Cooper et al., 2002).

\subsection{Age}

Recent literature suggests that although pornography consumption may be present across the life span, there are higher amounts of consumption among younger populations (Buzzell, 2005; Carroll et al., 2008; Cooper et al., 2002; McKee, 2007; Traeen, Spitznogle, \& Beverfjord, 2004). In a sample of Australians who reported a degree of pornography consumption, nearly $78 \%$ of them fell between the ages of $19-25$, whereas only approximately 33\% were between the ages of 26-35 (McKee, 2007). These findings corroborate the importance of considering age when evaluating users of pornography.

\subsection{Relationship status}

Despite the lack of consensus among the recent literature, many suggest that relationship status plays some part in consuming pornography (Albright, 2008; Bridges \& Morokoff, 2011; Carroll et al., in press; Cooper et al., 2002; Maddox et al., 2009). Albright (2008) found that divorced individuals were $25 \%$ more likely to consume pornography than singles. They also found that those who reported being married were $20 \%$ less likely to consume pornography than singles. Alternatively, Cooper et al. (2002) reported that $43.4 \%$ of those that reported participating in online sexual activities including pornography, were married. Others argue that relationship status is not significant when evaluating pornography use (Emmers-Sommer et al., 2013). This lack of consensus within the existing literature on relationship status suggests the importance of further evaluating this aspect of pornography users.

\subsection{Religiosity and acceptance}

Previous literature acknowledges the importance of religion when discussing sexuality (Lichter \& Carmalt, 2009). Thus, it is natural for religion to play a part in pornography use patterns. Researchers concur that pornography use and religiosity are negatively associated, specifically that those who are less religious are more likely to view pornography (Carroll et al., 2008; Nelson, Padilla-Walker, \& Carroll, 2010). Prior research has also illustrated that those who accept pornography use as an appropriate form of sexuality are more likely to view pornography (Carroll et al., 2008; Olmstead, Negash, Pasley, \& Fincham, 2013).

\subsection{Self-esteem}

Previous research has linked pornography use patterns with various forms of self-esteem of users. Some research suggests that increased pornography use is related to increased esteem (Kvalem, Træen, \& Iantaffi, 2016), whereas other research indicates that increased pornography use is related to decreased esteem (Morrison, Ellis, Morrison, Bearden, \& Harriman, 2006) or even depressive symptoms (Bridges \& Morokoff, 2011). One qualitative study of adolescents suggested higher forms of self-confidence was related to a decrease in pornography use patterns (LöfgrenMårtenson \& Mansson, 2010). This research indicates that when evaluating pornography users, it is of importance to also consider each individual's self-esteem.

\subsection{Motivation for use}

Men and women have illustrated a broad spectrum of motivations for consuming pornographic material (Albright, 2008; Cooper et al., 2002). In a sample of men who self-identify as having online sexual problems, two primary motivations for pornography use were identified (Cooper et al., 2004). First, some individuals used the internet to further their real-life sexual interactions. Second, some individuals used the internet as a substitute for their real-life sexual interactions. Although this sample only looked at men who reported having sexual problems, the two behavioral patterns that emerged may generalize to others as well. Presumably, the impacts would vary, both individually and on a romantic partner, if the motivation for the porn use was to enhance a sexual relationship with a partner, compared to if the motivation for porn use was to replace a sexual relationship with a partner.

Many individuals, especially women, view pornography as a part of their love making routine (Bridges \& Morokoff, 2011), to improve their sex lives with their current partner in such ways as being open to new things, to increase the ease of asking for sexual needs, and to increase their overall arousal during real-life sexual interactions (Albright, 2008; Grov, Gillespie, Royce, \& Lever, 2011). Other individuals, significantly more men, consume pornography for a more solitary sexual enhancement or a complete individual sexual experience (Albright, 2008; Bridges \& Morokoff, 2011; 
McKenna, Green, \& Smith, 2001). Some consumers of pornography have also reported that pornography can serve as a distraction, a way of coping with stress, and as a form of sexual education (Cooper et al., 2002; Paul \& Shim, 2008). Exploring classes of pornography users by including more detailed accounts of the motivations for use will assist in gaining a better understanding of pornography users.

\section{Toward a typology of pornography use}

Despite the recent influx of academic work examining pornography, much of the current research primarily focuses on pornography use in terms of simple frequencies while placing less consideration on the characteristics of the pornography user. Although these findings offer a foundation of the understanding of pornography use, it neglects crucial details of users of pornography, such as why they use pornography, what is gained from pornography use, and what unique risks and benefits are linked with various different patterns of porn use. To date, this literature has only minimally analyzed the possibility of different types of pornography users based on other factors outside of frequency, motivations, or the meaning of pornography use.

Current literature suggests varying characteristics or pornography patterns among users. For example, different types of use could lead to different outcomes on an individual and couple level. One study recently found that a couple's beliefs and agreement surrounding pornography consumption were related to their couple outcomes, such as lower relationship satisfaction, positive communication, and relationship stability (Willoughby, Carroll, Busby, \& Brown, 2016). Some literature also points to the importance of the relationship status of the individual in understanding the outcomes of pornography consumption (Bridges \& Morokoff, 2011; Olmstead et al., 2013). Some of this work also illustrates that the type of pornography being viewed, as well as duration of use, are important to partners within a couple context (Olmstead et al., 2013). This new literature, although emphasizing pornography in couple relationships, may more fully explain conflicting results regarding these individual outcomes and offer a conceptual foundation of pornography use that better accounts for the heterogeneity in the population.

Latent profile analysis further assists us in understanding pornography users as a heterogeneous rather than a homogenous population with distinct differences of individual characteristics and motivations to use pornography. On the ideographic and nomothetic continuum, the present study gravitates closer to focusing more on ideographic ideologies which emphasize more individual characteristics rather than nomothetic general trends (Hurlburt \& Knapp, 2006). This person-centered analysis groups individuals into typologies or classes. These classes contain individuals who are similar to one another and different from individuals in other classes (Muthén \& Muthén, 1998-2012). This allows us to view unique characteristics (idiographic) of pornography users beyond simple frequencies and general trends (nomothetic). Some work has delineated classes of individuals considering pornography use frequency and acceptance with various individual outcomes (Willoughby et al., 2014). This current study will build upon this literature by assessing pornography users and their motivations of use.

\section{The present study}

With previous research illustrating common themes in areas of pornography use frequency, attitudes towards the use of pornography, motivations of use, and links with religiosity and age we expect that there are various classes of pornography users based on the above characteristics that may mark differing types of users. Further, with previous scholars indicating consistent links between gender, relationship status, and self-esteem, we expect that these characteristics will be predictive of class membership.

Based on this previous research, we propose that multiple and varying classes of pornography users will be delineated in regards to specific markers such as motivations of pornography use, frequency of pornography use, age of user, degree of pornography acceptance, and religiosity. Further, class membership will be significantly predicted by gender, relationship status, and selfesteem. More specifically, among classes that are significantly characterized by women in romantic relationships, there will be lower frequency of pornography use, but when these classes do use pornography it will be for education purposes. These classes will be marked with higher rates of self-esteem. Alternately, among classes that are significantly characterized by men (in a relationship or not), there will be higher frequency of pornography use that is driven with the purpose of auto-erotic sexual experiences. These classes will be marked with lower rates of self-esteem. Also, we expect a class that illustrates those pornography users that, although infrequently use pornography, do so for a sense of escape or for self-soothing. Lastly, we expect that those classes that indicate greater frequency of pornography use will be younger in age, have higher rates of acceptance of pornography, and lower religiosity.

\section{Method}

\subsection{Sample and procedure}

These research questions were answered using an online survey of college students, completed through Qualtrics. Recruitment of participants occurred in an introductory human development course at a mid-western university in the United States by the instructor who incentivized participation through offering extra credit to those who participated. Informed consent was attained online before each participant could proceed to the survey. The survey in its entirety took approximately $45 \mathrm{~min}$ to complete and was administered in March of 2014. Four hundred and fifty-eight participants completed the survey online after initially being introduced to it in the classroom by the instructor. Due to large missingness on all scales related to this study, one participant was dropped from the analysis which brought the sample for the present study to 457 .

The sample was $88 \%$ White, 6\% African American, 5\% Latino, 4\% Asian, $2 \%$ Native American, and $1 \%$ other ethnicity. The sample was $64 \%$ female and $36 \%$ male, with $51 \%$ of the total sample reporting that they were in some form of a romantic relationship (e.g., dating, engaged, or married). Eighty-nine percent of the sample were $18-21$ years old, with $9 \%$ being $22-25$, and $3 \%$ being $26-45$.

\subsection{Measures}

Below are the measures that were used in the formation of classes of pornography users and predictors of those classes. The descriptives for each measure for the entire sample can be found in Table 2. 


\subsubsection{Pornography acceptance}

Pornography acceptance was assessed with one item that has been used as a part of other established questionnaires (RELATE; Nelson et al., 2010), which asked participants the amount of agreement with the statement: "viewing pornographic material (such as magazines, movies, and/or internet sites) is an acceptable way to express one's sexuality." this assessment of agreement was on a 6 -point Likert-like scale ranging from 1 (very strongly disagree) to 6 (very strongly agree).

\subsubsection{Pornography use}

Pornography use was assessed by a frequently used single item measure (Nelson et al., 2010), which asked, "During the past 12 months, on how many days did you view pornographic materials (such as magazines, movies, and/or Internet sites)?" Responses ranged from 1 to $6(1=$ none, $2=$ once a month or less, $3=2$ or 3 days a month, $4=1$ or 2 days a week, $5=3$ to 5 days a week, 6 = every day or almost every day).

\subsubsection{Motivations for pornography use}

Fourteen items that assessed motivations of pornography use were from the Pornography Consumption Inventory (Reid, Li, Gilliland, Stein, \& Fong, 2011). The stem for these items was, "Answer the following questions based on your personal behavior regarding pornographic consumption." Examples of items include: "I use it to learn more about sexual activity or practice," "I turn to it when I'm feeling down, sad, or lonely," and "I use it to help me masturbate, for a physical release." All fourteen of the items were on a scale ranging from 1 (never like me) to 5 (always like me). Because each of the 14 items evaluates different types of pornography use, each were included as an individual variable in the latent profile analysis.

\subsubsection{Religiosity}

Religiosity of the sample was assessed using the following question item found in previous research (Cline \& Ferraro, 2006), "In general, how important are religious or spiritual beliefs in your day-to-day life?" This question was on a 4-point scale ranging from 1 (very important) to 4 (not at all important). This item was reverse coded to correspond with a higher degree of religiosity or spirituality.

\subsubsection{Age}

Age of the participant was assessed by asking, "How old are you? (years is sufficient)," in which the participants were asked to numerically input their specific age.

\subsubsection{Predictors of class membership}

Gender, relationship status, and self-esteem were used to predict placement of participants in the respective classes. Both gender $(0=$ male, $1=$ female $)$ and relationship status $(0=$ single, $1=$ currently in a romantic relationship) were dichotomous variables. Self-esteem was assessed using the 10-item Rosenberg (1965) Self-Esteem Scale. This scale included questions such as, "On the whole, I am satisfied with myself," "I am able to do things as well as most other people," and "I feel that I'm a person of worth." Participants responded on a 4-point Likert-type scale from 1 (strongly disagree) to 4 (strongly agree). Items were coded to correspond with a higher degree of self-esteem, and the mean of these items was computed. The mean score for this scale was 3.19 $(S D=0.42)$ and reliability was acceptable $(\alpha=0.84)$.

\subsection{Data analysis}

The purpose of this study was to identify latent classes of pornography users, and to then identify potential predictors of those latent classes of pornography users. This was tested using a latent profile analysis using Mplus (Version 7; Muthén \& Muthén, 1998-2012), where a categorical latent variable was specified with the following variables as indicators of this latent variable: age, religiosity, pornography use, pornography acceptance, and 14 additional items that were various motivations for pornography use. Covariates of gender, relationship status, and self-esteem were used to predict class membership concurrently while deriving the number of classes that was a best fit to the data. As a protocol for identifying the best number of classes as a fit to the data, more classes were iteratively added, while assessing which number of classes was a best fit to the data. This best fit was determined by the log likelihood, Bayesian information criterion (BIC), Akaike's information criterion (AIC), and the Lo-Mendell-Rubin (LMR) likelihood ratio test. The lower log likelihood, BIC and AIC values reported by the analysis, the better fit of the models. The LMR was used to clarify the number of classes by comparing the current number of classes against one less class $(k-1)$ to determine if adding an additional class fit -significantly better than the previous model with one less class. Entropy values were also assessed to ensure the appropriate amount of classes for the sample; higher values of entropy indicate improved delineation of classes (Celeux \& Soromenho, 1996). The best fitting model is often when each person is their own class. However, due to the goal of parsimony and having a theoretically relevant model, the model fit statistics will be balanced with these considerations as well. To evaluate the relationship that the covariates of gender, relationship satisfaction, and self-esteem had with each specific class, a multinomial logistic regression was used where the largest class of users will be used as the reference class. This was performed by regressing each of the classes onto self-esteem, gender, and relationship status. Odds ratios were interpreted to illustrate the odds of membership in each class by each of the covariates.

\section{Results}

\subsection{Class formation}

To answer our first research question regarding the number of classes of pornography users derived from this dataset, we iteratively specified the latent categorical variable to be two classes, then three classes, then four classes, and then five classes. Model fit indices for models ranging from 1 to 5 classes are found in Table 1. The three-class solution was chosen as the best fitting model to the data that was also parsimonious and theoretically relevant. The three-class solution had a relatively low AIC and BIC values, high entropy, and the LMR value was $(p<0.10)$, showing improvement over the model with one- and two-classes. The three class model seemed to align well with previous research concerning pornography use patterns. Based on these model fit statistics, theory, and the goal of parsimony, the three-class model illustrated the best fit to this sample.

Table 1

Fit statistics for 1 to 5 class models with covariates of gender, relationship status, and self-esteem.

\begin{tabular}{llllll}
\hline Classes & Entropy & Loglikelihood & AIC & BIC & LMR \\
\hline 1 class & & -12831.51 & $25,747.02$ & $25,920.35$ & \\
2 class & 0.98 & -9452.59 & $19,021.19$ & $19,260.42$ & $-1937.63^{*}$ \\
3 class & 0.98 & -8876.66 & $17,913.32$ & $18,243.30$ & -9452.59 \\
4 class & 0.98 & -8606.68 & $17,417.36$ & $17,838.08$ & -8876.66 \\
5 class & 0.99 & -8398.84 & $17,045.67$ & $17,557.13$ & -8606.68 \\
\hline
\end{tabular}

Note: ${ }^{*} p<0.05$ 


\subsection{Three delineated classes}

The means of each indicator in the final three classes are found in Table 2. The three classes depicted different patterns of pornography acceptance and use as well as specific motivations of pornography use. The largest class, we labeled Porn Abstainers and had 285 participants ( $62.36 \%$ of the sample). The next largest class, we labeled Complex Porn Users and had 87 participants (19.04\% of the sample). The smallest class we labeled Auto-Erotic Porn Users which had 85 participants (18.6\% of the sample). Mean reports of age were approximately the same across all three classes. However, there was interesting variation in all the other indicators between these three latent classes of porn use.
Porn Users, they also indicated a broader variety of reasons for their usage. These other notable motivations reported included using pornography for a sense of excitement $(M=3.61)$ and expanding knowledge about sexual possibilities $(M=3.19)$, which indicated a more mixed pattern of use rather than solely as an auto-erotic experience. The lowest reported motivation for use was to avoid uncomfortable emotions $(M=1.97)$. These users also indicated the lowest reported religiosity among the three classes. Multinomial logistic regression results indicated that being a woman compared to being a man, odds were $98 \%$ lower of being in this class compared to the class of Porn Abstainers ( $b=-3.78, S E=0.38$, Odds Ratio $=0.02, p<0.001)$. Further, a one-unit increase in self-esteem was associated with a $75 \%$ decrease in the odds of being in this class

Table 2

Descriptive means and standard deviations of the overall sample and the descriptive means of the established three classes.

\begin{tabular}{|c|c|c|c|c|c|}
\hline \multirow[b]{2}{*}{ Observed Variable } & \multicolumn{2}{|c|}{$\begin{array}{l}\text { Overall } \\
(N=457)\end{array}$} & \multirow{2}{*}{$\begin{array}{l}\text { Porn abstainers }(n=285) \\
M\end{array}$} & \multirow{2}{*}{$\begin{array}{l}\text { Auto-Erotic porn users }(n=85) \\
M\end{array}$} & \multirow{2}{*}{$\begin{array}{l}\text { Complex porn users }(n=87) \\
M\end{array}$} \\
\hline & $M$ & $S D$ & & & \\
\hline Age & 19.74 & 1.95 & 19.52 & 19.98 & 20.26 \\
\hline Religiosity & 3.37 & 0.94 & 3.52 & 3.21 & 3.04 \\
\hline Pornography Use & 2.07 & 1.41 & 1.22 & 2.87 & 4.07 \\
\hline Pornography Acceptance & 2.79 & 1.52 & 2.16 & 3.45 & 4.18 \\
\hline \multicolumn{6}{|l|}{ Pornography Consumption Inventory } \\
\hline I use it to learn more about sexual activity or practice. & 1.61 & 0.88 & 1.18 & 2.01 & 2.63 \\
\hline It provides an opportunity to be distracted from life's challenges. & 1.43 & 0.83 & 1.02 & 1.55 & 2.64 \\
\hline I turn to it when I'm feeling down, sad, or lonely. & 1.29 & 0.68 & 1.02 & 1.34 & 2.13 \\
\hline I'm curious about what types of sex other people have. & 1.67 & 1.00 & 1.21 & 1.97 & 2.87 \\
\hline I use it to escape into a fantasy world. & 1.38 & 0.81 & 1.04 & 1.51 & 2.39 \\
\hline I use it to provide some novelty or variety in my life. & 1.40 & 0.81 & 1.03 & 1.52 & 2.51 \\
\hline I use it to sexually arouse myself. & 1.94 & 1.30 & 1.10 & 2.60 & 4.04 \\
\hline I use it to expand my knowledge about sexual possibilities. & 1.68 & 1.06 & 1.09 & 2.14 & 3.19 \\
\hline I use it to feel physical pleasure & 1.89 & 1.32 & 1.05 & 2.46 & 4.13 \\
\hline I use it to change my mood when I am anxious, stressed or angry. & 1.44 & 0.91 & 1.01 & 1.44 & 2.83 \\
\hline It gives me a sense of excitement. & 1.72 & 1.13 & 1.04 & 2.04 & 3.61 \\
\hline I use it to avoid feeling uncomfortable or unpleasant emotions. & 1.22 & 0.60 & 1.01 & 1.18 & 1.97 \\
\hline It fuels an interest I have to understand more about sex. & 1.56 & 0.96 & 1.09 & 1.93 & 2.75 \\
\hline I use it to help me masturbate for a physical release. & 1.92 & 1.36 & 1.07 & 2.48 & 4.19 \\
\hline
\end{tabular}

\subsubsection{Porn abstainers}

The Porn Abstainers class comprised about three-fifths of this sample, and had the lowest reports of pornography acceptance $(M=2.16)$, frequency $(M=1.22)$, and motivation for using pornography from among these three delineated classes. Although this class exhibited very low results across all pornography use patterns, the highest motivations behind viewing pornography for this class was a curiosity about types of sex others are having $(M=1.21)$ as well as a desire to educate oneself about sexual activity $(M=1.18)$. Further, the Porn Abstainers, on average, indicated higher religiosity than the other two classes and they also reported higher religiosity than the entire sample $(M=3.52)$.

\subsubsection{Complex porn users}

The Complex Porn Users comprised about one-fifth of the sample and was characterized by the highest reports of pornography acceptance, use, and various benefits they reported from using pornography. This class reported, on average, nearly four times the pornography use frequency and nearly double the acceptance of pornography use than the Porn Abstainers. The reported use in this class was approximately one to two days a week $(M=4.07)$. Although Complex Porn Users illustrated high reports of using pornography for personal sexual arousal $(M=4.04)$, physical pleasure $(M=4.13)$, and masturbation $(M=4.19)$ for their motivations of their pornography use patterns similar to Auto-Erotic compared to the class of Porn Abstainers $(b=-1.37, S E=0.38$, Odds Ratio $=0.25, p<0.05)$.

\subsubsection{Auto-Erotic Porn Users}

The smallest of the three classes labeled Auto-Erotic Porn Users, comprised about one-fifth of the sample, indicated moderate acceptance of pornography use $(M=3.45)$ and illustrated pornography use frequency between once a month or less and a few times a month $(M=2.87)$. The users in this class primarily indicated their motivations for pornography use were for personal sexual arousal $(M=2.60)$, a sexual release $(M=2.46)$, and masturbation $(M=2.48)$. The lowest reported motivation for use was to avoid uncomfortable emotions $(M=1.18)$.

Multinomial logistic regression results indicated that compared to the class of Porn Abstainers, women had a 93\% lower odds of being in the Auto-Erotic Porn User class compared to men $(b=-2.62, S E=0.35$, Odds Ratio $=0.07, p<0.001)$. Further, being in a romantic relationship compared to being single, odds were 2.12 times higher to be in the Auto-Erotic Porn User class than in the class of Porn Abstainers $(b=0.75, S E=0.36$, Odds Ratio $=2.12, p<0.05$ ). Lastly, a one-unit increase in self-esteem was associated with a $59 \%$ decrease in the odds of being in this class, Auto-Erotic Porn Users, compared to the class of Porn Abstainers ( $b=-0.89, S E=0.36$, Odds Ratio $=0.41, p<0.05)$. 


\section{Discussion}

The purpose of this study was to identify unique classes of pornography users and to identify potential predictors of being in one class relative to another. This was tested in a sample of 457 college students using a latent profile analysis and multinomial logistic regression. As, expected, three distinct classes or groups of pornography users were identified based upon pornography acceptance and use, motivations for pornography use, religiosity, and age. The three classes were labeled Porn Abstainers (62\%), Complex Porn Users (19\%), and Auto-Erotic Porn Users (19\%). Also as expected, those in classes using less pornography tended to be women and those with higher self-esteem. Surprisingly, college students in a relationship, compared to those were single, were more likely to be in the class of Auto-Erotic Porn Users relative to the class of Porn Abstainers.

Four unique storylines emerged among the three delineated classes. First, all classes exhibited fairly high religiosity despite moderate to high pornography acceptance and use. As noted earlier, family scholars concur that pornography use patterns and religiosity are negatively correlated as seen among Porn Abstainers (Carroll et al., 2008; Nelson et al., 2010). Although this surprising finding may simply be due to a more religious sample, there could be other factors at play. A recent study (Nelson et al., 2010), submits that it may not simply be the belief in religiosity, but also past and current religious practices that are negatively associated with pornography use. For the Auto-Erotic Porn Users and Complex Porn Users, one possibility could be that although these individuals report that religious beliefs are important in their lives, those beliefs may not be translating into specific religious practices (i.e., sexual abstinence), which have been associated with reductions in pornography use. These classes, with higher pornography use, despite fairly high religiosity, suggests that there are other facets of religion that are negatively associated with pornography beyond mere religiosity which were not evaluated in the present study.

A second storyline among all three classes is that using pornography to avoid uncomfortable emotions and turning to pornography when feeling down, sad, or lonely, had some of the lowest reports for all three classes. This illustrates that although many college students are using pornography for sexual arousal, physical pleasure, and assistance in masturbation as illustrated in two of the three classes, few even among high users are using it as a tool to escape or self-soothe. With previous research depicting the practice of using pornography as an attribute of those with a compulsive addiction to pornography (Cooper et al., 2002; Paul \& Shim, 2008), the present sample suggests that this may not be common among college populations. This finding is surprising especially considering that previous research has suggested that college students experience notable rates of stress and therefore enact various coping strategies to curb it (Brougham, Christy, Mendoza, \& Miller, 2009).

A third storyline worth noting is that Auto-Erotic Porn Users reported trends that when using pornography, they do so with the intent of becoming sexually aroused, receiving physical pleasure, and to masturbate. However, this is not the sole case for the Porn Abstainers and Complex Porn Users. The Porn Abstainers reported very minimal pornography usage but seemingly when they did use pornography the intent was centered on curiosity of how others are engaging in sex rather than for their own sexual pleasure. Complex Porn Users, although reporting the highest motivations to use pornography for masturbation and physical pleasure, also indicated that they use pornography for expanding knowledge about sexual possibilities. This possibly suggests what previous research has indicated as pornography not only being an avenue for sexual arousal, but to also explore and learn about sex (Watson \& Smith,
2012). Further, these college students, who many of which are ages $18-30$, may be a part of a formative time in their lives where they are exploring new parts of themselves, relationships, and sexual activity (Arnett, 2015). For those reporting these motivations of use, viewing pornography could possibly be a safer choice than to actually engage in real life sexual experiences to explore one's sexuality and learn more about how others are engaging in sex.

The fourth storyline centered on the predictors of class membership including gender, relationship status, and self-esteem. As expected, results indicated participants that reported higher selfesteem scores had lower odds being placed in the Complex or Auto-Erotic Porn User Classes compared with the class of Porn Abstainers. In one notable study, Nelson et al. (2010) suggested that higher levels of self-worth were related to lower pornography use patterns. The present study's findings reinforce the negative correlation of self-esteem and pornography use. Due to the present study only offering statistical associations we cannot state cause and effect, however, our results corroborate that they are linked in some capacity.

Further, as expected, the present study supports literature that suggests women have much lower odds of being a part of a class that has higher pornography use patterns (Auto-Erotic and Complex Porn Users) than one that has much lower pornography use patterns (Porn Abstainers). Although some popular media outlets point towards rising pornography use among women (Brennan, 2010; Carey, 2011), current academic literature suggests that pornography use is predominantly a phenomenon encountered by men (Albright, 2008; Buzzell, 2005; Carroll et al., 2008; Cooper et al., 2002; Cooper et al., 2004; Emmers-Sommer et al., 2013; McKee, 2007; Stack et al., 2004).

Lastly, participants that reported being in a relationship were surprisingly over twice as likely of being placed in the Auto-Erotic Porn Users class rather than the Porn Abstainers class. Some academic literature points to pornography use being a sexual outlet in lieu of a real-life sexual partner resulting in higher uses of pornography among single populations (Albright, 2008; Bridges \& Morokoff, 2011; McKenna et al., 2001). The present study challenges these assumptions by presenting findings that suggest those who are in relationships are more likely to be a part of a grouping where there is higher use of pornography and where pornography is predominantly used as an auto-erotic experience. We speculate that some college students in romantic relationships may use pornography at a higher rate than those who are single, as a way to supplement real-life sexual experiences. Some literature suggests that pornography use is associated with being more comfortable trying new things sexually as well as being more comfortable with one's body image (Watson \& Smith, 2012). This unique finding could suggest a pattern of pornography use that is driven by becoming comfortable with sexuality, with one's partner, or gaining a form of experience to better perform for a real partner. Coupled with our finding that women are $93 \%$ less likely to be in the Auto-Erotic Porn Use class compared to the class of Porn Abstainers, this possibly indicates that those viewing pornography at higher rates while also in relationships are predominantly men.

\subsection{Limitations and future directions}

Although the present study builds upon previous scholarly work and suggests new information on pornography users' unique characteristics, it is not without its limitations. Most notably, the present study analyzes a university sample of college students who predominantly report being women. This sample is not nationally representative and therefore limits its generalizability. Further, although this study was not conducted at a religious institution, the present sample reported high rates of religiosity. Despite the 
present study's religiosity aligns quite closely with recent reports of the millennial generation, which indicate that approximately $68 \%$ have some form of religious affiliation (Pew Research Center, 2010), findings should be interpreted with hesitancy with the knowledge that pornography use and religiosity are linked (Nelson et al., 2010). Also, due in part to pornography research still being in its early stages, there is a lack of consensus of appropriate measures of pornography use and pornography use patterns. Although the Pornography Consumption Inventory (Reid et al., 2011) used in the present study illuminates more detail regarding motivations behind pornography use, the measures used to evaluate frequency of use are limited in such a way that they do not consider specific types of pornography use or duration of pornography use episodes. This information could more fully depict spectrums of pornography use patterns. Lastly, as noted earlier, pornography use has been shown to be a difficult variable to accurately and consistently test due to the varying definitions and understandings of pornography from each participant. For example, what one person considers pornography, another considers a regular movie.

The present study emphasizes the importance of examining a behavior that has increasingly become an accepted and practiced form of sexuality. Further academic work needs to be completed creating detailed measures that accurately and consistently assess pornography use beyond simple frequencies (see Willoughby \& Busby, 2016). As illustrated in this study, it is vital that these measures consider facets of pornography use such as motivations, duration of pornography use, gender differences, type of pornography use, and how the behavior may currently fit into their relationships. These measures will assist in viewing pornography users as unique individuals with different purposes of their pornography patterns, rather than a homogenous behavior. The present study suggests that pornography use is related to those in romantic relationships. Further research is needed to better understand pornography use within a couple context. Lastly, because much of the pornography literature is inconsistent with individual and relational outcomes, potential moderators need to be identified that may change the expected impact of pornography of individuals and couples.

\section{Conclusion}

Building upon existing scholarly work, the present study sheds additional light upon pornography users and their characteristics through an analysis that illustrates heterogeneity rather than homogeneity among pornography users. This study assists us to further understand pornography users by classifying them into three classes we labeled Porn Abstainers, Auto-Erotic Porn Users, and Complex Porn Users. Each of these classes have unique characteristics concerning pornography acceptance, use, motivations for use, religiosity, and age. This study emphasizes the importance of taking a more detailed look at pornography users and promoting a more accurate and holistic approach to understanding pornography use.

\section{References}

Albright, J. M. (2008). Sex in America online: An exploration of sex, marital status, and sexual identity in internet sex seeking and its impacts. Journal of Sex Research, 45, 175-186.

Arnett, J. J. (2015). Emerging adulthood: The winding road from the late teens through the twenties. New York, NY: Oxford University Press.

Brennan, R. (2010, June 7). Getting to know you: Let's talk about porn... Glamour. Retrievedfrom http://www.glamour.com/sex-love-life/blogs/smitten/2010/06/ getting-to-know-you-lets-talk-3.html.

Bridges, A. J., \& Morokoff, P. J. (2011). Sexual media use and relational satisfaction in heterosexual couples. Personal Relationships, 18, 562-585.

Brougham, R. R., Christy, Z. M., Mendoza, C. M., \& Miller, J. R. (2009). Stress, sex differences, and coping among college students. Current Psychology, 28, 85-97. Buzzell, T. (2005). Demographic characteristics of persons using pornography in three technological contexts. Sexuality \& Culture: An Interdisciplinary Quarterly, 9, 28-48.

Carey, T. (2011, April 7). Why more and more women are using pornography. The Guardian. Retrieved from http://www.theguardian.com/culture/2011/apr/07/ women-addicted-internet-pornography.

Carroll, J. S., Padilla-Walker, L. M., Nelson, L. J., Olson, C. D., Barry, C., \& Madsen, S. D. (2008). Generation XXX: Pornography acceptance and use among emerging adults. Journal of Adolescent Research, 23, 6-30.

Carroll, J. S., Willoughby, B. J., Busby, D. M., \& Brown, C. C. The pornography gap: Differences in men's and women's pornography patterns in couple relationships. Journal of Couple \& Relationship Therapy (in press)

Celeux, G., \& Soromenho, G. (1996). An entropy criterion for assessing the number of clusters in a mixture model. Journal of Classification, 13, 195-212.

Cline, K., \& Ferraro, K. F. (2006). Does religion increase the prevalence and incidence of obesity in adulthood? Journal for the Scientific Study of Religion, 45, 269-281.

Cooper, A., Galbreath, N., \& Becker, M. A. (2004). Sex on the internet: Further our understanding of men with online sexual problems. Psychology of Addictive Behaviors, 18, 223-230.

Cooper, A., Morahan-Martin, J., Mathy, R. M., \& Maheu, M. (2002). Toward an increased understanding of user demographics in online sexual activities. Journal of Sex \& Marital Therapy, 28, 105-129.

Edelman, B. (2009). Red light states: Who buys online adult entertainment? Journa of Economic Perspectives, 23, 209-220.

Emmers-Sommer, T., Hertlein, K., \& Kennedy, A. (2013). Pornography use and attitudes: An examination of relational and sexual openness variables between and within gender. Marriage \& Family Review, 49, 349-365.

Grov, C., Gillespie, B., Royce, T., \& Lever, J. (2011). Perceived consequences of casual online sexual activities on heterosexual relationships: A U. S. Online survey. Archives of Sexual Behavior, 40, 429-439.

Hurlburt, R. T., \& Knapp, T. J. (2006). Münsterberg in 1898, not Allport in 1937, introduced the terms 'Idiographic' and 'Nomothetic' to American psychology. Theory and Psychology, 16, 287-293.

Kvalem, I. L., Træen, B., \& Iantaffi, A. (2016). Internet pornography use, body ideals, and sexual self-esteem in Norwegian gay and bisexual men. Journal of Homosexuality, 63, 522-540.

Lichter, D. T., \& Carmalt, J. H. (2009). Religion and marital quality among lowincome couples. Social Science Research, 38, 168-187.

Löfgren-Mårtenson, L., \& Mansson, S. (2010). Lust, love, and life: A qualitative study of Swedish adolescents' perceptions and experiences with pornography. The Journal of Sex Research, 47, 568.

Maddox, A. M., Rhoades, G. K., \& Markman, H. J. (2009). Viewing sexually-explicit materials alone or together: Associations with relationship quality. Archives of Sexual Behavior, 40, 441-448.

Malamuth, N. M., Hald, G., \& Koss, M. (2012). Pornography, individual differences in risk and men's acceptance of violence against women in a representative sample. Sex Roles, 66, 427-439.

McKee, A. (2007). The relationship between attitudes towards women, consumption of pornography, and other demographic variables in a survey of 1,023 consumers of pornography. International Journal of Sexual Health, 19, 31-45.

McKenna, K. Y. A., Green, A. S., \& Smith, P. K. (2001). Demarginalization of the sexual self. Journal of Sex Research, 38, 302-311.

Morrison, T. G., Ellis, S. R., Morrison, M. A., Bearden, A., \& Harriman, R. L. (2006). Exposure to sexually explicit material and variations in body esteem, genital attitudes, and sexual esteem among a sample of Canadian men. Journal of Men's Studies, 14, 209-222.

Muthén, L. K., \& Muthén, B. O. (1998-2012). Mplus user's guide ( $7^{\text {th }}$ ed.). Los Angeles, CA: Muthén \& Muthén.

Nelson, L. J., Padilla-Walker, L., \& Carroll, J. S. (2010). "I believe it is wrong but I still do it": A comparison of religious young men who do versus do not use pornography. Psychology of Religion and Spirituality, 2, 136-147.

Olmstead, S. B., Negash, S., Pasley, K., \& Fincham, F. D. (2013). Emerging adults' expectations for pornography use in the context of future committed romantic relationships: A qualitative study. Archives of Sexual Behavior, 42, 625-635.

Paul, B., \& Shim, J. W. (2008). Gender, sexual affect, and motivations for Internet pornography use. International Journal of Sexual Health, 20, 187-199.

Pew Research Center. (2010). Religion among the millennials: Less religiously active than older Americans, but fairly traditional in other ways. Retrieved May 17, 2016 from http://www.pewforum.org/files/2010/02/millennials-report.pdf.

Price, J., Patterson, R., Regnerus, M., \& Walley, J. (2016). How much more xxx is generation $x$ consuming? Evidence of changing attitudes and behaviors related to pornography since 1973. Journal of Sex Research, 53, 12-20.

Reid, R. C., Li, D. S., Gilliland, R., Stein, J. A., \& Fong, T. (2011). Reliability, validity, and psychometric development of the pornography consumption inventory in a sample of hypersexual men. Journal of Sex \& Marital Therapy, 37, 359-385.

Rosenberg, M. (1965). Society and the adolescent self-image. Princeton, NJ: Princeton University Press.

Sinkovic, M., Stulhofer, A., \& Bozic, J. (2012). Revisiting the association between pornography use and risky sexual behaviors: The role of early exposure to pornography and sexual sensation seeking. Journal of Sex Research, 50, 633-641.

Stack, S., Wasserman, I., \& Kern, R. (2004). Adult social bonds and use of internet pornography. Social Science Quarterly, 85, 75-88.

Træen, B., Spitznogle, K., \& Beverfjord, A. (2004). Attitudes and use of pornography in the Norwegian population 2002. Journal of Sex Research, 41, 193-200.

Watson, M., \& Smith, R. D. (2012). Positive porn: Educational, medical, and clinical uses. American Journal of Sexuality Education, 7, 122-145. 
Willoughby, B. J., \& Busby, D. M. (2016). In the eye of the beholder: Exploring variations in the perceptions of pornography. The Journal of Sex Research, 53, 678-688.

Willoughby, B. J., Carroll, J. S., Busby, D. M., \& Brown, C. (2016). Differences in pornography use among romantic couples: Associations with satisfaction, stability, and relationship processes. Archives of Sexual Behavior, 45, 145-158.

Willoughby, B. J., Carroll, J. S., Nelson, L. J., \& Padilla-Walker, L. (2014). Associations between relational sexual behaviour, pornography use, and pornography acceptance among US college students. Culture, Health \& Sexuality, 16, 1052-1069.

Wright, P. J. (2012). Pornography consumption, cocaine use, and casual sex among U.S adults. Psychological Reports, 111, 305-310.

Wright, P. J. (2013). U.S. males and pornography, 1973-2010: Consumption, predictors, correlates. Journal of Sex Research, 50, 60-71.

Yucel, D., \& Gassanov, M. A. (2010). Exploring actor and partner correlates of sexual satisfaction among married couples. Social Science Research, 39, 725-773. 